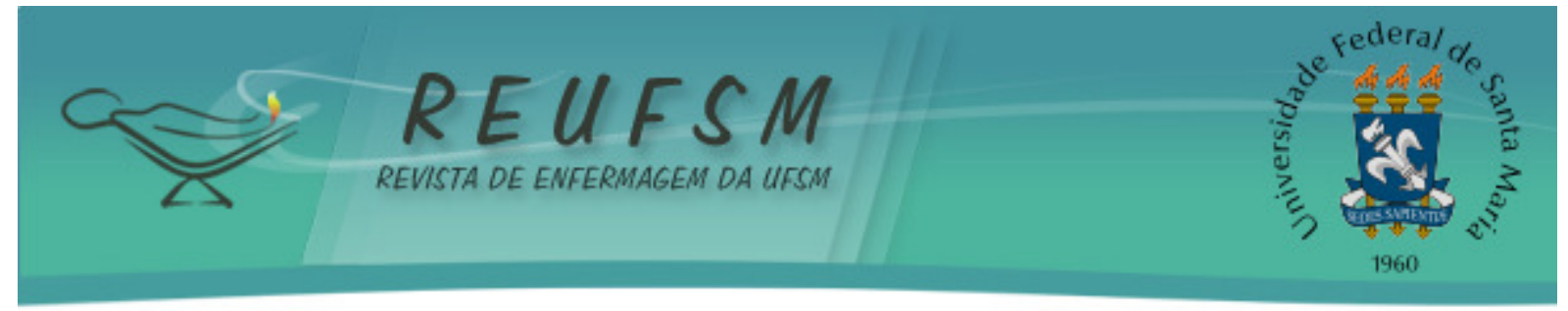

ARTIGO ORIGINAL

\title{
ATENÇÃO À MULHER EM PROCESSO DE ABORTAMENTO INDUZIDO: A PERCEPÇÃO DE PROFISSIONAIS DE ENFERMAGEM
}

\section{ATTENTION TO WOMAN IN CASE OF INDUCED ABORTION: THE PERCEPTION OF PROFESSIONAL NURSING}

\section{ATENCIÓN A LA MUJER EN CASO DE ABORTO PROVOCADO: LA PERCEPCIÓN DEL PROFESIONAL DE ENFERMERÍA}

Doi: $10.5902 / 2179769214801$

Eveline Franco da Silva ${ }^{1}$ Dinifer Concatto Trevisan ${ }^{2}$

Elisiane Lorenzini ${ }^{3}$ Ana Carla dos Santos Fischer Pruss ${ }^{4}$ Marcia Rejane Strapasson ${ }^{5}$ Ana Lucia de Lourenzi Bonilha ${ }^{6}$

RESUMO: Objetivo: conhecer a percepção de profissionais de enfermagem em relação à atenção à mulher em processo de abortamento induzido. Método: estudo descritivo, qualitativo, realizado com 12 profissionais de enfermagem do centro obstétrico de um hospital público da Região Sul do Brasil. Os dados, originados de entrevistas semiestruturadas, foram fundamentados na análise temática. A pesquisa foi aprovada por Comitê de Ética em Pesquisa. Resultados: da análise emergiram duas categorias: o papel da enfermagem no atendimento à mulher em processo de abortamento induzido; e não estar capacitada para o atendimento à mulher em processo de abortamento induzido. Conclusão: as profissionais entrevistadas não se sentiam capacitadas para o atendimento e percebiam que exerciam o cuidado de forma mecânica. É necessário instrumentalizar os profissionais por meio de capacitações que desenvolvam habilidades e conhecimentos específicos acerca do atendimento humanizado à mulher nesta condição.

Descritores: Aborto induzido; Cuidados de enfermagem; Aborto; Enfermagem; Saúde da mulher.

ABSTRACT: Aim: to know the perception of nurses toward to the assistance to women in induced abortion process. Method: descriptive, qualitative study with 12 nursing professionals from the obstetric center of a public hospital in Southern of Brazil. The data, originated from semi-structured interviews, were analyzed based in thematic analysis. The study was approved by the Ethics Committee. Results: two categories emerged: the role of nursing in care for women in induced abortion process; and not being

\footnotetext{
1 Enfermeira Obstetra, Mestre em Enfermagem pela Universidade Federal do Rio Grande do Sul (UFRGS), Docente do Curso de Enfermagem da Faculdade da Serra Gaúcha (FSG), Caxias do Sul, Rio Grande do Sul, Brasil. E-mail: evelinefranco@yahoo.com.br

${ }^{2}$ Enfermeira, Graduada em Enfermagem pela Faculdade Nossa Senhora de Fátima, Caxias do Sul, Rio Grande do Sul, Brasil. E-mail: dinitrevisan@gmail.com

${ }^{3}$ Enfermeira, Mestre em Ciências da Saúde, Doutoranda em Enfermagem pela UFRGS com período sanduíche University of British Columbia/Canadá, Porto Alegre, Rio Grande do Sul, Brasil. E-mail: elisilorenzini@gmail.com

${ }^{4}$ Enfermeira Obstetra, Mestre em Enfermagem pela UFRGS, Enfermeira do Centro Obstétrico do Hospital de Clínicas de Porto Alegre (HCPA), Porto Alegre, Rio Grande do Sul, Brasil. E-mail: enffischer@yahoo.com.br

${ }^{5}$ Enfermeira Obstetra, Mestre em Enfermagem pela UFRGS, Enfermeira do Hospital Universitário Mãe de Deus, Canoas, Rio Grande do Sul, Brasil. E-mail: marciarejane@yahoo.com.br

${ }^{6}$ Enfermeira Obstetra, Doutora em Enfermagem pela Universidade de São Paulo, Professora Titular da UFRGS, Porto Alegre, Rio Grande do Sul, Brasil. E-mail: bonilha.ana@gmail.com
} 


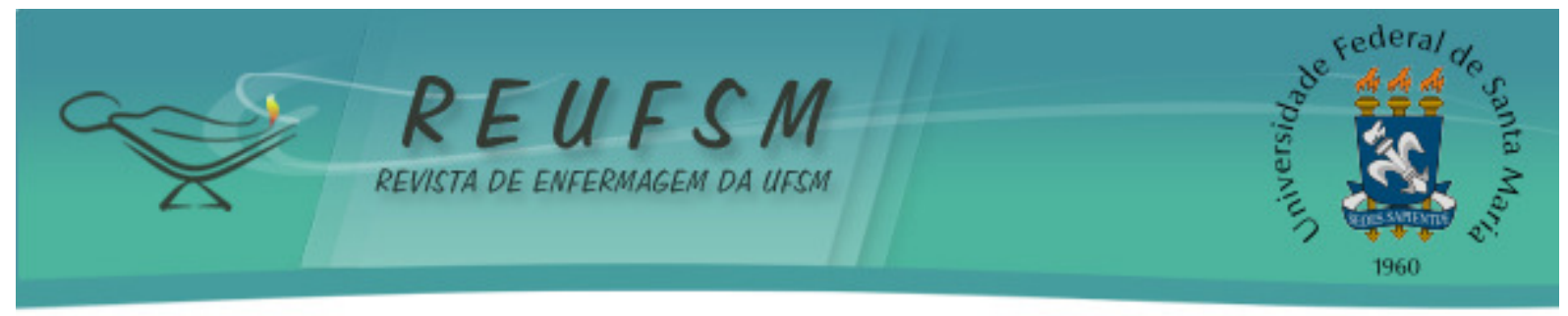

able to care for women in induced abortion process. Conclusion: the interviewed professionals did not feel qualified to assist and realized that they cared mechanically. We need to equip professionals through training to develop specific skills and knowledge about the humane treatment of women in this condition.

Descriptors: Induced abortion; Nursing care; Abortion; Nursing; Women's health.

RESUMEN: Objetivo: conocer la percepción de profesionales de enfermería sobre la atención a la mujer en proceso de aborto provocado. Método: estudio descriptivo, cualitativo, con 12 profesionales de enfermería del centro obstétrico de un hospital de la región sur de Brasil. Los datos originales de entrevistas fueron fundamentados en el análisis temático. La investigación fue aprobada por el Comité de Ética en Investigación. Resultados: fueron identificadas dos categorías: el rol de la enfermería en la atención a la mujer en proceso de aborto provocado; y el hecho de no estar capacitada para el atendimiento a la mujer en proceso de aborto inducido. Conclusiones: las profesionales no se sienten capacitadas para el atendimiento. Es necesario instrumentalizar los profesionales a través de capacitaciones que desarrollen habilidades y conocimientos específicos sobre el atendimiento humanizado a la mujer en dicha condición.

Descriptores: Aborto inducido; Atención de enfermería; Aborto; Enfermería; Salud de la mujer.

\section{INTRODUÇÃO}

A atenção à saúde da mulher é uma das prioridades do governo brasileiro. Nesse sentido, a Política Nacional de Atenção Integral à Saúde da Mulher incorpora, na perspectiva de gênero, a integralidade e a promoção da saúde como princípios norteadores e busca consolidar os avanços no campo dos direitos sexuais e reprodutivos. Portanto, promover a saúde à mulher, incluindo a atenção ao abortamento em condições seguras, consiste em um dos objetivos específicos dessa política. A estratégia proposta para esse alcance refere-se à qualificação e à humanização da atenção à mulher em situação de abortamento. ${ }^{1}$

0 abortamento é definido como a interrupção da gestação até a $20^{\mathrm{a}}$ ou $22^{\mathrm{a}}$ semana de gravidez e com expulsão do concepto com peso inferior a 500 gramas e/ou estatura menor ou igual a $25 \mathrm{~cm}$. 0 aborto é a expulsão do produto da concepção e sua etiologia é classificada como aborto espontâneo ou provocado/induzido. ${ }^{2} \mathrm{O}$ aborto induzido, ou interrupção voluntária da gestação, é reconhecido mundialmente como um problema de saúde pública, uma vez que atinge mulheres de todas as etnias e classes sociais, especialmente aquelas com maior dificuldade de acesso aos serviços de saúde e menores recursos econômicos e sociais. ${ }^{3-4} 0$ aborto induzido está associado ao alto índice de mortalidade materna em decorrência de suas complicações, a exemplo das hemorragias e infecções. ${ }^{1,4-5}$

A maioria dos abortos com complicações ou sequelas irreversíveis ocorre em países em desenvolvimento. ${ }^{2}$ No Brasil o índice de abortamento é de $31 \%$ das gestações, com aproximadamente 1,44 milhão de abortos espontâneos e inseguros, com taxa de 3,7 para cada 100 mulheres. ${ }^{6}$ Ressalta-se que estes dados, em função do caráter restritivo da lei em vigor, podem ser ainda maiores, pois as estatísticas nem sempre refletem a realidade, 0 que dificulta a avaliação da magnitude do problema no país. ${ }^{1-2}$ Admite-se o aborto em casos de estupro ou quando a vida da mulher está em risco ${ }^{7}$ e, recentemente, em 2012, foi aprovado pelo Congresso Nacional, o aborto como um ato legal em caso de gestante de feto anencéfalo, desde que comprovado por laudos médicos. ${ }^{8}$ Excetuando-se essas situações, a interrupção voluntária da gestação é considerada um ato ilícito penal, sendo considerado um crime contra a vida. 


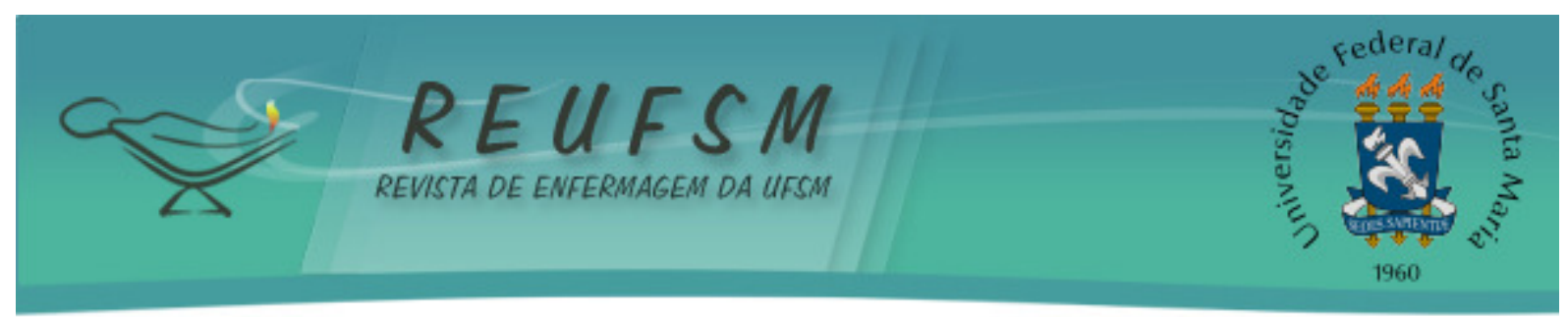

O aborto é um tema complexo e polêmico, alvo de críticas e questionamentos, principalmente no que se refere aos aspectos legais, bioéticos e religiosos. Nesse contexto, atitudes condenatórias e preconceituosas não são raras nas instituições de saúde durante o atendimento à mulher em processo de abortamento induzido, ocorrendo, por vezes, o descaso e postergação do atendimento. ${ }^{9}$ É reconhecido que, durante o atendimento prestado à mulher, muitos profissionais agem de acordo com suas crenças e valores, deixando clara sua visão a respeito deste assunto. ${ }^{10}$ Além disso, a literatura enfatiza que os profissionais da área da saúde não dominam a legislação sobre aborto e adquirem atitudes discriminativas, explícitas em palavras. ${ }^{10-11}$ Esses aspectos vêm sendo observados pelas políticas públicas de atenção à mulher no intuito de sensibilizar os profissionais que prestam atendimento no processo de abortamento induzido para o desenvolvimento de um atendimento digno e sem juízos. ${ }^{2}$

A proximidade das autoras com essa temática ocorreu por meio das atividades assistenciais e de docência no cuidado à mulher, que possibilitou atender muitas mulheres em situação de abortamento induzido e, ao observar o comportamento dos profissionais de saúde nesse contexto, levantou-se o questionamento: como os profissionais de enfermagem percebem $o$ atendimento prestado à mulher no processo de abortamento induzido? A realização desta pesquisa justificou-se pela possibilidade de compreender a percepção dos profissionais de enfermagem no atendimento à mulher em situação de abortamento e, a partir disso, permitir reflexões que visem à adoção de condutas que possam subsidiar os processos de cuidado de uma atenção qualificada e humanizada. Frente ao exposto, considerando a Política de Atenção Integral à Saúde da Mulher, o objetivo deste estudo foi conhecer a percepção de profissionais de enfermagem em relação à atenção à mulher em processo de abortamento induzido.

\section{MÉTODO}

Trata-se de um estudo descritivo com abordagem qualitativa, realizado no Centro Obstétrico de um hospital público da Região Sul do Brasil. Participaram da pesquisa 12 profissionais de enfermagem, sendo duas enfermeiras e oito técnicas em enfermagem. A determinação do número de participantes fundamentou-se no critério de saturação dos dados. ${ }^{12}$

Para seleção das participantes foram considerados os critérios de inclusão: ser profissional de enfermagem; e atuar no referido centro obstétrico por período maior que seis meses. Os critérios de exclusão foram: estar ocupando cargo de chefia ou gestão na unidade, uma vez que os enfermeiros que ocupam estes cargos na instituição não prestam atendimento direto à mulher; e estar afastado do trabalho durante o período de coleta de dados.

A coleta de dados ocorreu nos meses de março a abril de 2012, utilizando-se a técnica de entrevista semiestruturada. ${ }^{13}$ No instrumento de pesquisa continham questões de caracterização dos participantes e um roteiro de entrevista elaborado pelas autoras, contendo sete perguntas abertas sobre o atendimento de enfermagem à mulher em situação de abortamento induzido. As entrevistas realizaram-se nas instalações da referida unidade, em horários previamente agendados, que não alteraram o fluxo do processo de trabalho, sendo preservada a privacidade e evitando-se interrupções. Para melhor aproveitamento dos dados, com autorização das participantes, as entrevistas foram audiogravadas e, posteriormente, transcritas para análise.

Os dados foram analisados por meio do método de análise temática de Bardin, ${ }^{13}$ seguindo as fases de pré-análise; exploração do material; e tratamento, inferência e interpretação dos resultados obtidos. ${ }^{13}$ Desse processo emergiram duas categorias: o papel 


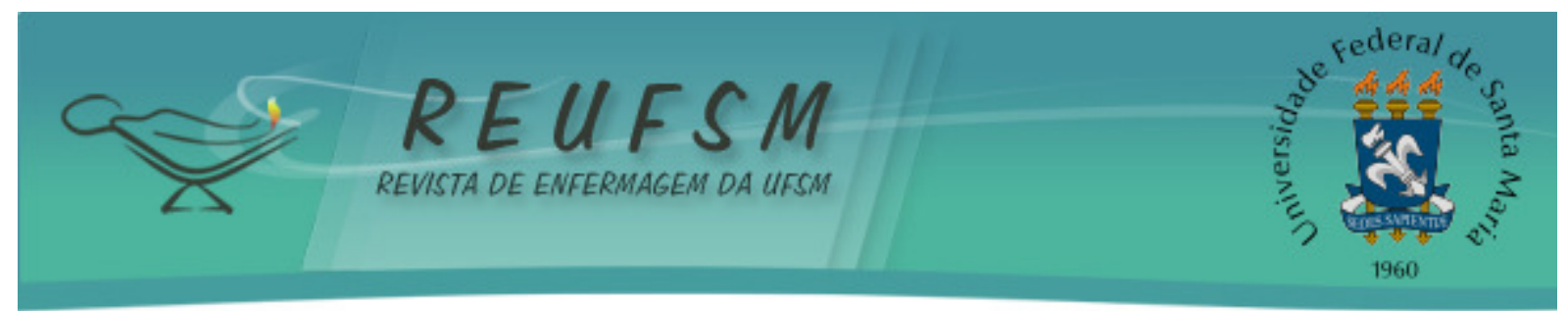

da enfermagem no atendimento à mulher em processo de abortamento induzido e não estar capacitada para o atendimento à mulher em processo de abortamento induzido.

As participantes do estudo assinaram o Termo de Consentimento Livre e Esclarecido, do qual receberam uma cópia. A presente pesquisa contemplou a Resolução 466/2012 ${ }^{14}$ e foi aprovada pelo Comitê de Ética em Pesquisa da Associação Cultural e Científica Virvi Ramos, com número de Protocolo 006/12. ${ }^{14}$ A fim de garantir o anonimato, as participantes foram identificadas com a letra $E$ (entrevistada) seguida de um número (E1, E2, ..., E10), conforme a ordem cronológica de realização das entrevistas.

\section{RESULTADOS E DISCUSSÃO}

Todas as participantes do estudo caracterizaram-se por serem do sexo feminino e estarem na faixa etária entre 30 anos e 55 anos. 0 tempo de atuação em centro obstétrico variou entre um ano e 14 anos. As enfermeiras e técnicas em enfermagem não possuíam cursos de especialização ou capacitações/treinamentos na área da obstetrícia.

\section{O papel da enfermagem no atendimento à mulher em processo de abortamento induzido}

Quando as mulheres chegam aos serviços de saúde em processo de abortamento, espontâneo ou induzido, suas experiências permeiam as dimensões física, emocional e social. Portanto, preconiza-se que no atendimento a essas mulheres os profissionais promovam uma escuta qualificada, pois o abortamento é considerado como uma situação de enfrentamento na qual os diversos sentimentos vivenciados expõem a mulher a um momento de fragilidade pessoal. ${ }^{2}$ Essa afirmativa foi constatada na fala de uma participante:

o nosso papel é ajudar e dar assistência a elas nesse momento [...] ouvir, principalmente, porque é um momento difícil. (E10)

A escuta é considerada uma forma de acolhimento, que faz parte de um tratamento digno e respeitoso oferecido à mulher. A atenção às necessidades psicossociais da mulher que passa por um aborto é específica e realizada por psicólogos e assistentes sociais. No entanto, ressalta-se que 0 atendimento multiprofissional nesta ocasião permite um cuidado integral, contemplando o atendimento humanizado. Nesse contexto, a equipe de enfermagem possui um importante papel pois, geralmente, é quem recebe a mulher no centro obstétrico e a acompanha nos procedimentos e recuperação clínica. ${ }^{2,9}$ Portanto, neste momento a escuta qualificada caracteriza-se como um instrumento fundamental do atendimento humanizado.

Nesse sentido, aconselha-se a adoção de abordagens comunicativas que respeitem a autonomia das mulheres e seu poder de decisão, procurando estabelecer uma relação de confiança. ${ }^{2}$ Para nortear as ações de enfermagem é importante que o atendimento humanizado à mulher contemple os princípios fundamentais da bioética: respeito pela pessoa, beneficência, não maleficência e justiça. ${ }^{15}$ Conforme é ilustrado no depoimento de E1, o papel da enfermagem no atendimento à mulher em processo de abortamento induzido configura-se por respeitar a individualidade.

respeitar a individualidade dela, se ela não fala da situação [...] nosso papel é oferecer conforto, atender, respeitar a individualidade. Tem que se colocar à disposição: Quer conversar? A 


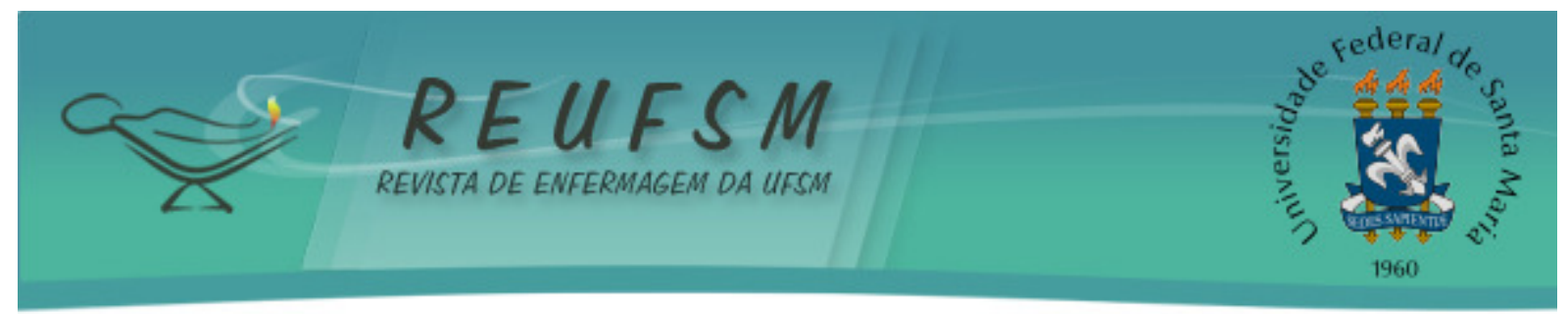

gente está aqui para te ouvir. Não quer falar, a gente respeita. (E1)

Endente-se que neste processo de abortamento induzido seja importante respeitar a autonomia da mulher pelas suas escolhas e respeitar sua dor e silêncio, além de salvaguardar seu bem-estar e garantir-lhe o direito ao atendimento qualificado e humanizado. Dessa forma, seria pertinente que os profissionais de enfermagem atuantes nesse contexto desenvolvessem habilidades que favorecessem o estabelecimento de uma escuta ativa e de uma relação de empatia, bem como adotassem uma postura que possibilitasse a comunicação sintonizada com as demandas de cada mulher.

É essencial que os profissionais desenvolvam a capacidade de escuta sem prejulgamentos e imposições de valores, pois esses são pontos que permitem à mulher verbalizar seus sentimentos e suas necessidades. ${ }^{2} \mathrm{Na}$ percepção de E11, o principal papel da enfermagem no atendimento à mulher em processo de abortamento vai ao encontro da atenção humanizada e qualificada nesse contexto:

não julgar, que é o principal [...] aceitar elas do jeito que vierem. (E11)

Ainda que as profissionais participantes deste estudo verbalizassem que o principal papel da enfermagem seja não julgar, a realidade distancia-se da Política de Atenção Integral à Saúde da Mulher. $O$ abortamento induzido continua sendo um tema não discutido nos serviços de atendimento à mulher, tornando mais distante o alcance da atenção humanizada plena, sem discriminação de qualquer natureza. ${ }^{10-11} \mathrm{Na}$ fala de $\mathrm{E} 5$, é implícito que o julgamento estava presente nas ações de cuidado e nas relações entre profissionais e mulheres.

Claro, a gente sempre dá uns conselhozinhos, mas na verdade [...] Não caberia à gente ficar julgando o porquê fez isso. (E5)

Refletir sobre as convicções pessoais não é uma tarefa fácil, porém torna-se uma atividade fundamental para aprender a aceitar o outro com suas escolhas e valores. Ao lidar com mulheres em situação de abortamento, os profissionais de saúde necessitam pensar sobre suas influências no atendimento à saúde, pois esta postura reflexiva contribui para a adoção de condutas destituídas de julgamentos arbitrários e rotulações. ${ }^{2,15}$ Nessa perspectiva, a atenção qualificada está atrelada à sensibilização dos profissionais de enfermagem sobre os múltiplos olhares relacionados à individualidade das mulheres, desvinculando os olhares discriminatórios. ${ }^{2}$

No entanto, viabilizar a humanização nas instituições de saúde pressupõe transcender a habitual prática de atendimento, voltada apenas para o tratamento de doenças, para operacionalização de ações que visem à satisfação da mulher por meio de um atendimento de qualidade, fundamentado na integralidade e promoção da saúde. ${ }^{2} \mathrm{~A}$ humanização do atendimento implica também em assegurar o melhor tratamento.

Porém, a literatura revela que a dificuldade de ouvir as mulheres e tratá-las como sujeitos com desejos, crenças e temores causa fracasso durante o atendimento humanizado à mulher em situação de abortamento. ${ }^{10}$ Estudos revelam que os profissionais de enfermagem priorizam o atendimento à mulher em processo de parto e nascimento, não considerando a abordagem humanitária e os riscos que envolvem as mulheres que provocam aborto. ${ }^{16-17}$

Uma investigação com objetivo de identificar o conhecimento e a percepção dos profissionais da saúde em relação à legislação brasileira sobre o aborto induzido constatou 


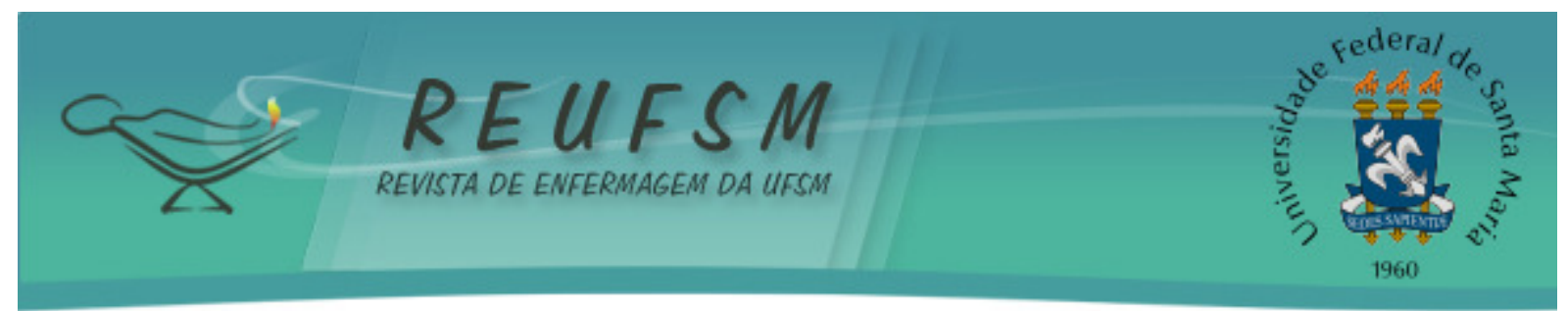

que muitos profissionais de enfermagem desconhecem a legislação em questão e que, de modo geral, todos profissionais de saúde apresentaram atitudes de discriminação, julgamento e preconceito no atendimento às mulheres que provocam o aborto. ${ }^{15} 0$ conhecimento da legislação sobre aborto, bem como dos procedimentos técnicos e avaliação de sinais clínicos são importantes no cuidado de enfermagem, contudo não esgotam o campo de atuação do enfermeiro e do técnico de enfermagem. Inclusive, para que a atenção ao abortamento seja humanizada, a mulher deve ser informada de todos os procedimentos e a escuta é essencial nesse processo. ${ }^{2,16}$

Embora as políticas públicas de saúde alertem para o atendimento qualificado e humanizado, as participantes do estudo revelaram que não percebiam o atendimento como uma ação humanizada. Na percepção das participantes, o cuidado de enfermagem ocorria de forma mecanicista, centrado na execução de técnicas, conforme é explícito nas falas:

[...] atendimento com relação à dor [...] dar as melhores condições [...] de higiene, conforto, medicação, providenciar com agilidade os exames que vão pedir e deixar ela confortável. (E11)

nossa obrigação é atender a paciente, medicar a paciente. (E5)

por mais que falam em humanização, eu acho muito desumano, sabe? Tu faz uma coisa muito automática, geralmente as pacientes chegam sangrando bastante e aí a primeira coisa que tu faz é tirar a roupa, pegar um acesso, colocar sangue, é bem mecânico, sabe? Às vezes tu tem tempo, já parei para conversar [...] mas é aquela coisa bem mecânica. (E8)

Os dados anteriores são reforçados por outros estudos. ${ }^{9,10}$ Estudo de revisão sobre o cuidado de enfermagem à mulher em situação de aborto mostra que as relações entre mulheres que provocam o aborto e profissionais de saúde centram-se apenas nos procedimentos técnicos, não contemplando os demais aspectos que constituem 0 atendimento integral à mulher. ${ }^{10}$ Pesquisa ${ }^{9}$ sobre as práticas de enfermagem na atenção às mulheres em situação de abortamento evidenciou que os profissionais dão ênfase aos aspectos clínicos e terapêuticos do atendimento à mulher em processo de abortamento induzido, e isso revela a fragilidade e lacunas da formação acadêmica de enfermagem, muitas vezes pautada na visão reducionista das técnicas e das exigências burocráticas na prestação de cuidado.

Acolher e fornecer informações consiste em uma prática de responsabilidade de todos os profissionais que atendem a mulher em situação de abortamento. ${ }^{16}$ Nesse sentido, ressalta-se que o acolhimento e o fornecimento de informações constituem-se em componentes do cuidado que necessitam estar presentes de forma transversal durante todo o atendimento. $\mathrm{O}$ acolhimento não se limita a meras técnicas e à escuta qualificada, mas refere-se a uma prática educativa que deve refletir a qualidade da relação entre profissionais de saúde e mulher. ${ }^{2}$ Ao encontro dessa proposta de acolhimento, algumas participantes referiram que o papel da enfermagem na atenção ao abortamento consiste na educação, orientação e aconselhamento da mulher:

o papel da enfermagem nesse momento [...] é educativo, tentar orientar ela para que isso não volte a ocorrer. (E4)

aconselhamento, orientação [...]. (E12) 


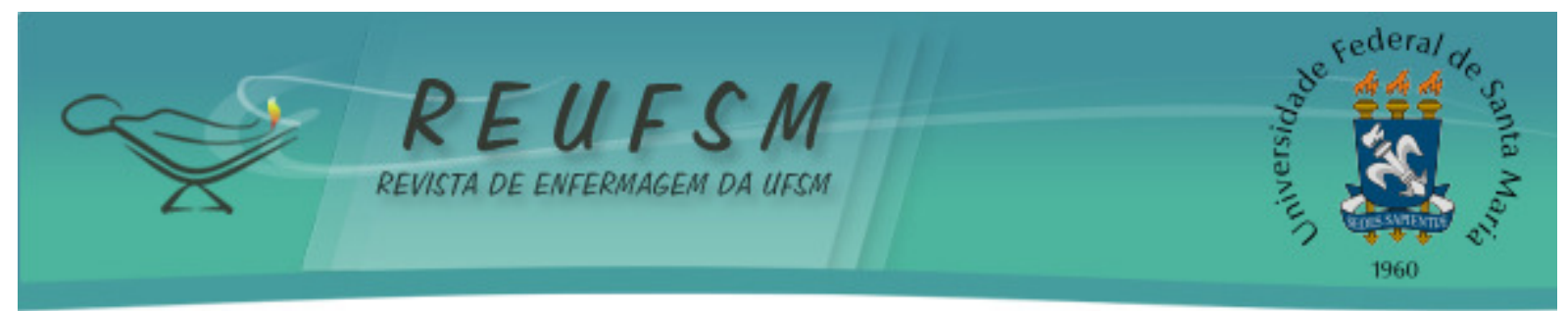

A equipe de enfermagem tem como papel educar e orientar. Para que ocorra um atendimento de qualidade à mulher os profissionais necessitam estar integrados quanto aos aspectos técnicos, éticos e legais do aborto, evitando-se o julgamento e o preconceito. ${ }^{16} \mathrm{~A}$ comunicação é um instrumento fundamental para uma educação efetiva, representando a base de sustentação das ações de enfermagem, e é apresentada nos aspectos éticoprofissionais e jurídicos da Atenção Humanizada ao Abortamento. ${ }^{2}$

Conforme mencionado anteriormente, destaca-se que a educação implica no fornecimento de orientações à mulher para reconhecê-la como sujeito da ação de saúde, contemplando o autocuidado e respeitando a tomada de decisão de cada mulher, de acordo com as diretrizes do Sistema Único de Saúde. ${ }^{1-2}$ Portanto, a orientação fornecida à mulher em processo de abortamento induzido também deve respeitar o princípio da autonomia.

\section{Não estar capacitada para o atendimento à mulher em processo de abortamento induzido}

É desvelado nas falas das profissionais, ilustrada por E2, que estas procuravam não se envolver no atendimento à mulher quando o aborto era induzido, deixando o acolhimento apenas para a equipe médica.

como a gente tem médicos o tempo todo e quase sempre eles que fazem essa parte, não é? [...] A gente atende como se fosse tipo: teve um aborto espontâneo... A gente fica na da gente. (E2)

A abordagem multiprofissional à mulher em processo de abortamento deve ser promovida e exercida de forma que a mesma sinta-se respeitada na sua liberdade, promovendo sua dignidade, e autonomia moral e ética na tomada de decisão. Esses profissionais precisam lidar com preconceitos, estereótipos e discriminações que possam prejudicar e desumanizar o atendimento. Assim sendo, o acolhimento à mulher em situação de abortamento é responsabilidade de todos os membros da equipe de saúde. ${ }^{2}$

Além disso, as profissionais referiram ter mais facilidade em atender mulheres que tiveram o aborto espontaneamente:

quando acontece aborto espontâneo é fácil [...] Tu conversas, tu tentas fazer, de repente, a pessoa ver o outro lado. [...] Agora com a pessoa que provoca [aborto] é difícil, como é que tu vais falar alguma coisa se a pessoa tirou [...]? (E1)

No relato anterior, a profissional referiu que o atendimento à mulher em processo de abortamento espontâneo era fácil, pois conseguia estabelecer uma comunicação e conversa com a mulher buscando confortá-la. Prestar atendimento a quem espera por um filho e o perde também é evento complexo, pois envolve muitos sentimentos, como: perda, angústia e incapacidade de gerar um filho saudável.

Acredita-se que a partir da comunicação efetiva, que proporcione um atendimento humanizado, o enfermeiro possa exercer um cuidado direcionado à mulher que contribua para construção de uma sociedade melhor, na qual sejam respeitados os direitos e a dignidade da mulher. Por isso, é necessário que o profissional de enfermagem, ao longo de sua formação acadêmica, e por meio de capacitações permanentes na sua vida profissional, seja um profissional reflexivo sobre sua prática. ${ }^{18}$

As lacunas existentes, desde o processo de formação acadêmica, são responsáveis 


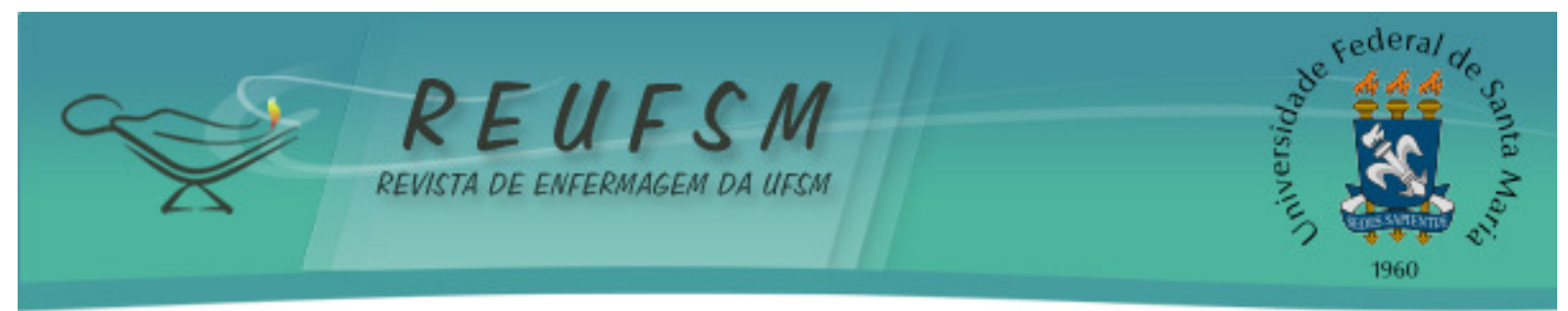

por muitos atendimentos de baixa qualidade e pouco humanizados prestados às mulheres brasileiras. Esse tipo de atendimento está presente em todas as classes profissionais da área da saúde. ${ }^{16}$

As políticas de saúde enfatizam que os profissionais de saúde devem atender às mulheres respeitando os princípios bioéticos, seus direitos humanos reprodutivos, de forma que seja possível exercer de fato, em todo território nacional, uma saúde pública universal, integral e equânime. ${ }^{2}$ No entanto, estudo qualitativo realizado em uma maternidade pública brasileira infere que os profissionais não são preparados para lidar com os sentimentos, as demandas sociais da mulher em processo de abortamento e demais elementos que ultrapassam a dimensão biomédica. ${ }^{9}$

Nesse contexto, as participantes da pesquisa revelaram não se sentirem capacitadas para prestar atendimento à mulher em processo de abortamento. Além disso, trouxeram em seus discursos pensamentos e atitudes discriminatórias, contraditórias ao atendimento humanizado, como:

capacitada não. Qualquer coisa que te tira a atenção daqui, tu não vais ter aquela paciência de sentar e conversar e ouvir elas, às vezes [...] chega um aborto e tu estás aqui com raiva do mundo, tu vais descontar nessa mãe. (E10)

o que tu vais dizer? "Ah, tu fizeste aborto! Não estás vendo? Matou uma vida." Então eu trato da mesma forma, como se estivesse vindo ganhar um filho. Eu não falo nada, fico na minha. (E3)

eu não me sinto capacitada. [...] Às vezes tenho vontade de dizer assim: Poxa! Mas tu não tens cabeça, por que tu fizeste isso? Agora aguenta as consequências, tu fica quieta. [...] Mas não posso fazer isso. Não me sinto preparada, às vezes eu não sei o que dizer. (E4)

Essas informações revelam as fragilidades da atenção à mulher que aborta. Quando os profissionais não refletem sobre suas ações, pensamentos e relações no processo de trabalho, o cuidado de enfermagem pode se tornar fragmentado, muitas vezes, inclusive, repercutindo em um ato de violência institucional. ${ }^{17}$ Porém, os depoimentos das participantes mostram, sobretudo, a necessidade de aperfeiçoamento com capacitações e discussões sobre o assunto, mesmo sendo esse tema tão polêmico e, muitas vezes, constrangedor. Entende-se que nessas circunstâncias a competência e as habilidades dos profissionais são ameaçadas, pois se percebe a dificuldade de interação com a mulher.

Os discursos discriminatórios, o preconceito e a interferência de crenças e valores dos profissionais impossibilitam que o atendimento seja realizado em prol das necessidades das mulheres, negligenciando-lhes o suporte emocional, que cabe a todos os profissionais, especialmente, aos profissionais de enfermagem que permanecem por mais tempo próximos à mulher. ${ }^{2,16}$

Por outro lado, entende-se que a comunicação pelas profissionais entrevistadas pode ter sido prejudicada em razão da organização do próprio serviço de enfermagem.

às vezes tu não tens tempo nenhum. Isso me frustra muito [...] porque tu não tens tempo, tu não paras para conversar. (E8)

$\mathrm{Na}$ fala de E8 constata-se a frustração da profissional por não conseguir conversar com a mulher em processo de aborto em razão do tempo. A organização e sistematização 


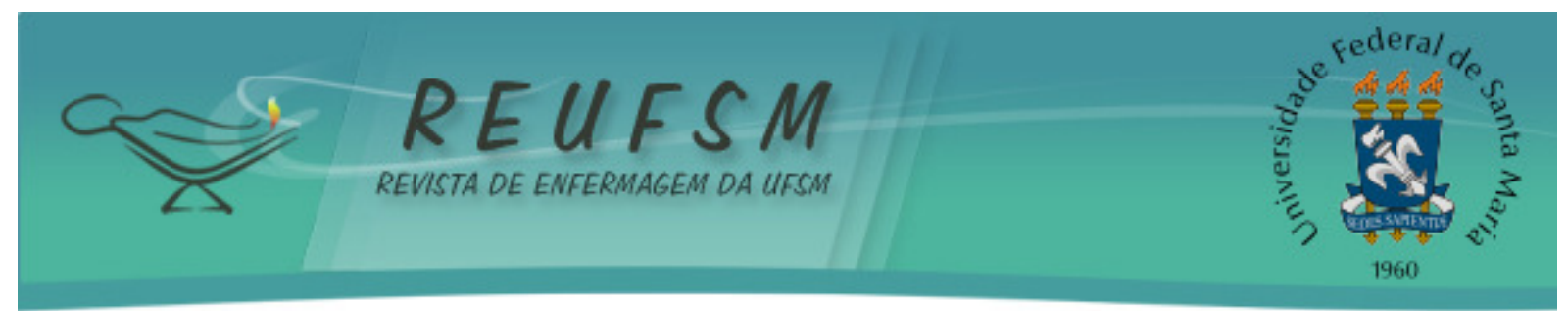

do atendimento podem favorecer as ações de enfermagem que permitam o atendimento humanizado, contribuindo para atender aos esforços da Política de Atenção Integral à Saúde da Mulher.

\section{CONSIDERAÇÕES FINAIS}

0 estudo permitiu conhecer a percepção de profissionais de enfermagem em relação à atenção à mulher em processo de abortamento induzido. Verificou-se que os profissionais percebem a atenção prestada de forma mecanicista, centrada na sistematização de técnicas, na qual a humanização não é reconhecida e/ou exercida e a escuta é desarticulada do processo de cuidar. Nesse contexto, profissionais de enfermagem, algumas vezes transferem o acolhimento aos médicos, não seguindo o atendimento preconizado pela Política de Atenção Integral à Saúde da Mulher.

Apesar de ser uma política constituída, o cuidado humanizado no processo de abortamento ainda é pouco percebido na prática assistencial; e tampouco este é respeitado como poder de decisão e escolha da mulher. $O$ atendimento à mulher em processo de abortamento induzido é permeado de pré-conceitos e subjetividades, constituindo-se em uma linha de cuidado fragmentada, distante da integralidade, universalidade e equidade.

Acredita-se que este estudo contribui para a reflexão acerca do cuidado e das condutas éticas frente ao atendimento prestado pelos profissionais de enfermagem à mulher em situação de abortamento induzido. Dessa forma, sugere-se para a prática de enfermagem a instrumentalização por meio de capacitações profissionais que desenvolvam habilidades e conhecimentos específicos acerca do atendimento humanizado, provocando a sensibilização para o atendimento que respeite os direitos humanos sexuais e reprodutivos e os princípios bioéticos nesse contexto.

Considera-se que este estudo não apresentou limitações que comprometessem seus resultados. No entanto, reconhece-se que outros métodos de pesquisa poderiam fornecer resultados mais amplos. Portanto, recomenda-se que sejam desenvolvidos mais estudos sobre a atenção de enfermagem no texto da mulher em situação de abortamento, para que seja possível modificar o atendimento de enfermagem à mulher em situação de abortamento induzido sob a perspectiva da ética, do direito e da humanização.

\section{REFERÊNCIAS}

1. Brasil. Ministério da Saúde. Política Nacional de Atenção Integral à Saúde da Mulher: princípios e diretrizes. $1^{\text {a }}$ ed. Brasília (DF): Ministério da Saúde; 2011.

2. Brasil. Ministério da Saúde. Atenção humanizada ao abortamento: norma técnica. Brasília (DF): Ministério da Saúde; 2011.

3. Mulat A, Bayu $\mathrm{H}$, Mellie $\mathrm{H}$, Alemu A. Induced second trimester abortion and associated factors in amhara region referral hospitals. BioMed Res Int [Internet]. 2015 mar [acesso em 2015 abr 27]; 2015:256534. Disponível http://www.hindawi.com/journals/bmri/2015/256534/. http://dx.doi.org/10.1155/2015/256534.

Doi:

4. Vallely LM, Homiehombo $P$, Kelly-Hanku A, Whittaker A. Unsafe abortion requiring hospital admission in the Eastern Highlands of Papua New Guinea - a descriptive study of women's and health care workers' experiences. Reprod Health. 2015;12(1):22.

5. Sedgh G, Singh S, Shah IH, Âhman E, Henshaw SK, Bankole A. Induced abortion: 


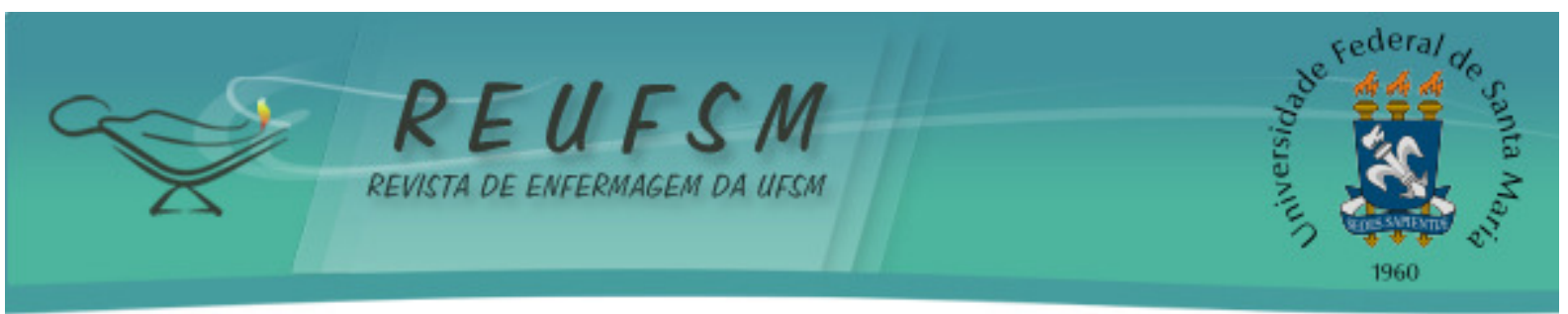

incidence and trends worldwide from 1995 to 2008. The Lancet. 2012;379(9816):625-32.

6. Brasil. Ministério da Saúde. Aborto inseguro: um problema de saúde pública [Internet]. 2011 [acesso em 2012 jun 11]. Disponível em: http: / / portal.saude.gov.br/saude/visualizar_texto.cfm?idtxt=22411.

7. Anjos KF, Santos VC, Souzas R, Eugênio BG. Aborto e saúde pública no Brasil: reflexões sob a perspectiva dos direitos humanos. Saúde Debate [Internet]. 2013 [acesso em 10 jun 2014];37(98):504-15.

Disponível

em: http://www.scielo.br/pdf/sdeb/v37n98/a14v37n98.pdf.

8. Brasil. Supremo Tribunal Federal (STF). Arguição de Descumprimento de Preceito Fundamental 54: interrupção de gravidez de feto anencéfalo [Internet]. 2012 [acesso em 2015 abr 29]. Disponível em: http://www.stf.jus.br/arquivo/informativo/documento/informativo661.htm. (Informativo STF; 661).

9. Soares MCS, Freitas VÉO, Cunha ARR, Almeida JLS, Souto CMRM, Dantas RA. Práticas de enfermagem na atenção às mulheres em situação de abortamento. Rev RENE [Internet]. 2012 [acesso em 2015 abr 29];13(1):140-6. Disponível em: http: / / www.revistarene.ufc.br/revista/index.php/revista/article/view/25.

10. Strefling ISS, Lunardi Filho WD, Demori CC, Soares MC, Santos CP. Cuidado de enfermagem à mulher em situação de aborto: revisão integrativa. Rev Enferm UFSM [Internet]. 2015 [acesso em 2015 abr 29];5(1):169-77. Disponível em: http://cascavel.ufsm.br/revistas/ojs-2.2.2/index.php/reufsm/article/view/12533/pdf.

11. Cacique DB, Junior RP, Osis MJMD. Opiniões, conhecimento e atitudes de profissionais da saúde sobre o aborto induzido: uma revisão das pesquisas brasileiras publicadas entre 2001 e 2011. Saúde Soc [Internet]. 2013 [acesso em 2015 abr 29];22(3):916-36. Disponível em: http://www.revistas.usp.br/sausoc/article/view/76487.

12. Fontanella BJB, Luchesi BM, Saidel MGB, Ricas J, Turato ER, Melo DG. Amostragem em pesquisas qualitativas: proposta de procedimentos para constatar saturação teórica. Cad Saúde Pública. 2011;27(2):388-94.

13. Bardin L. Análise de conteúdo. $5^{\mathrm{a}}$ ed. Lisboa: Edições 70; 2009.

14. Brasil. Ministério da Saúde. Conselho Nacional de Saúde. Resolução CNS n 466, de 12 de dezembro de 2012. Diretrizes e normas regulamentadoras de pesquisas envolvendo seres humanos. Diário Oficial da União [da] República Federativa do Brasil, Basília; 2013 jun 13. Seção 1, p. 59-62.

15. Peres EC, Barbosa IA, Silva MJP. Cuidado humanizado: o agir com respeito na concepção de aprimorandos de enfermagem. Acta Paul Enferm [Internet]. 2011 [acesso em 2015 jun 22];24(3):334-40. Disponível em: http://www.scielo.br/pdf/ape/v24n3/05.

16. Benute GRG, Nonnenmacher D, Nomura RMY, Lucia MCS, Zugaib M. Influência da percepção dos profissionais quanto ao aborto provocado na atenção à saúde da mulher. Rev Bras Ginecol Obstet. 2012;34(2):69-73.

17. Gesteira SMA, Diniz NMF, Oliveira EM. Assistência à mulher em processo provocado: discurso de profissionais de enfermagem. Acta Paul Enferm. 2008;21(3):449-53.

18. Cechinel C, Caminha MEP, Becker D, Lanzoni GMM, Erdmann AL. Vivência gerencial de acadêmicos de enfermagem: em pauta a sistematização da assistência de enfermagem. Rev Enferm UFSM [Internet]. 2012 [acesso em 2015 abr 29];2(1):190-7. Disponível em: 


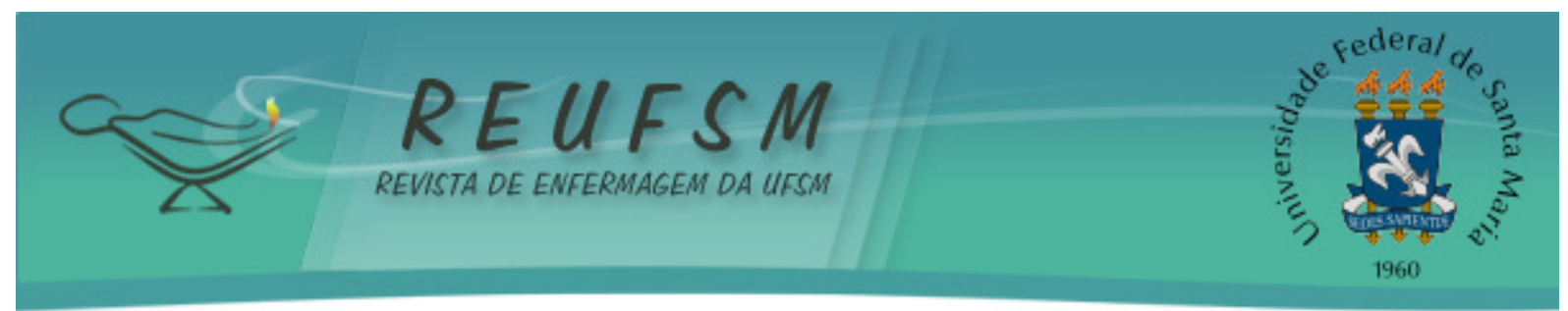

http://cascavel.ufsm.br/revistas/ojs-2.2.2/index.php/reufsm/article/view/3652/3150.

Data de recebimento: $11 / 07 / 2014$

Data de aceite: 24/06/2015

Contato do autor responsável: Eveline Franco da Silva

Endereço postal: Rua Os Dezoito do Forte, 2366 - Caxias do Sul, Rio Grande do Sul, Brasil, CEP: $95.020-472$.

E-mail: evelinefranco@yahoo.com.br 